\section{A Perspective of the Kenyan Space Programme: Past, Present and the Future}

\section{Anthony M Mwangudza ${ }^{1 *}$, Andrew O Nyawade ${ }^{2}$, John N Kimani ${ }^{2}$ and Margaret Maimba ${ }^{3}$}

\begin{abstract}
Kenya recognizes that a powerful component of technology that drives world economies is space technology and its applications. To manage these developments, the Kenyan government in 2009 gazetted the Kenya National Space Secretariat to initiate the process of formulating a National Space Programme and realize the Kenya Space Agency by 2012.

Also, a key component in development is communication and data sharing, which is essential in rapid disbursement of space based data and related information. The optical fibre network (National Optical Fibre Backbone Infrastructure - NOFBI) has been rolled out all over Kenya to ensure the determination of the government's endeavour to connect the entire country so as to have access to these data.

Farther, sufficient qualified technical personnel and research scientists have been trained in various aspects of space activities, and are currently working in their specific fields of specialization. About thirty Kenyan professionals have been trained and are practicing in space science and technology related fields both locally and abroad. Comparatively, from these capacity building initiatives and experiences, Kenya has achieved a fairly critical mass necessary to pursue the next level of becoming a space faring nation. This document therefore enumerates the achievements realised so far by the Kenyan government, the local research community and partners in space related activities and prospects for the future.

However, there are challenges which have to be overcome in order to realize the full potential of this vision. These include updating of the space policy and legislation, political, bureaucratic and financial considerations, infrastructure and capacity building, and the high cost of accessing space technology.
\end{abstract}

\section{Keywords}

Vision 2030; Kenyan space programme; Kenya space strategy

\section{Introduction}

Kenya is currently pursuing the goal of attaining a newly industrialized nation status by the year 2030. The basis of this dream, VISION 2030 [1], is that our national economic programme shall be science and technology driven. And, a powerful component of technology that drives world economies is space technology and its applications. Therefore, it is imperative that the Government invests

*Corresponding author: Anthony M Mwangudza, San Marco Project, Malindi, Kenya, Tel: +254 42 2120999; E-mail: mmwangudza@yahoo.com, anthony.mwangudza@asi.it

Received: February 22, 2013 Accepted: May 05, 2013 Published: May 16 2013 in space enterprise, espouses space technology transfer and institutes capacity building in space science and technology. This will enable Kenya to be in a position to claim a share of the global space industry.

Kenya's gross domestic product is set to increase 18 times in the next eight years if it focuses on innovation and training. Kenya by 2020 could command 20 per cent of the Africa's GDP of about Ksh249 trillion (USD 3 trillion) [2], i.e. Ksh 54.8 trillion (USD 0.6 trillion), if innovations and human capital become the nation's growth focus. The optical fibre network (National Optical Fibre Backbone Infrastructure - NOFBI), shown in Figure 1, which has been rolled all over Kenya is a pointer to the determination of the government's endeavour to connect the entire country, a key component in communication and data sharing, which is essential in rapid disbursement of space based related information and products [3].

Current Capacity and Progress in Space Science and Technology in Kenya

Recently (2010) the University of Nairobi started a degree course in Astrophysics and Astronomy. The Kenyan scientific community is also geared towards research in space science and technology as evidenced by the programmes that are rolled out in related fields in our institutions of higher learning.

Three other universities, namely Jomo Kenyatta University of Agriculture and Technology, Moi University and Egerton University are considering offering specific courses to specialize in space engineering and remote sensing at undergraduate and post graduate levels.

The taskforce committee set by the government to implement the National Space Secretariat agenda has developed the organization chart for the operations of the secretariat as shown in Figure 2 [4].

Currently, enough qualified technical personnel and research scientists have been trained in remote sensing, orbital mechanics and navigation, spacecraft payloads and platforms, communications,



Figure 1: The National optical fibre backbone infrastructure. 
space mission analysis and design, and various aspects of space activities. These professionals are currently working in their specific fields of specialization. At present, Kenya has achieved a critical mass necessary to pursue the next level in space development. There are now 8 Kenyans who have completed Ph.D. programmes in space science and technology, 5 Engineers with Masters in astronautics, 7 Engineers with Bachelors degree in Astronautics, 15 technologists and 3 graduates in Space law working for the local space industry.

To fulfill the aims of the Kenyan space initiative, the secretariat through sourcing adequate funding from the government, lobbying in the country's legislature and private sector engagement and possible partnership with foreign collaborations, expects to have in place the following human capacity by 2025: 10 mission design and payload analysts, 5 rocket and launch specialists, 10 orbit, attitude control and navigation specialists, 10 structures and materials engineers, 20 telecommunications engineers, 20 computer engineers and software developers, and 30 ground control technologists working for the space agency. It is expected that more specialists will be working for the local industry who would have received their training within the country or abroad. The secretariat, again, through the public private sector partnerships will also avail the necessary resources to establish the infrastructure for the space programme to take off (Figure 3).

\section{Expected Milestones of the Kenyan Space Programme} by 2017

The Kenya Space Agency is planning to set up a High Resolution Picture Transmission (HRPT) Satellite Receiving Station at the Department of Resource Survey and Remote Sensing in Nairobi while

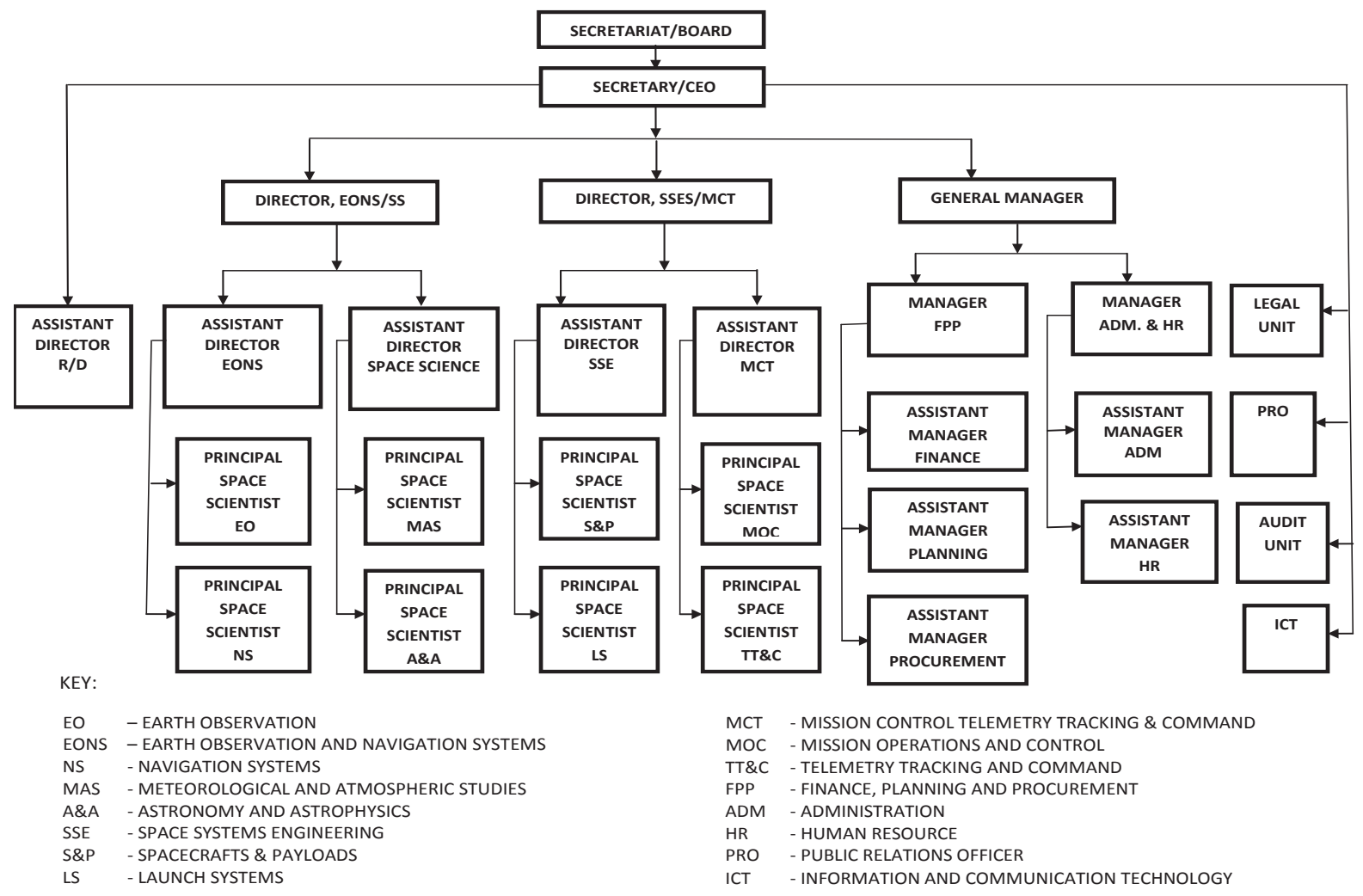

Figure 2: The Kenya National Space Secretariat organization chart

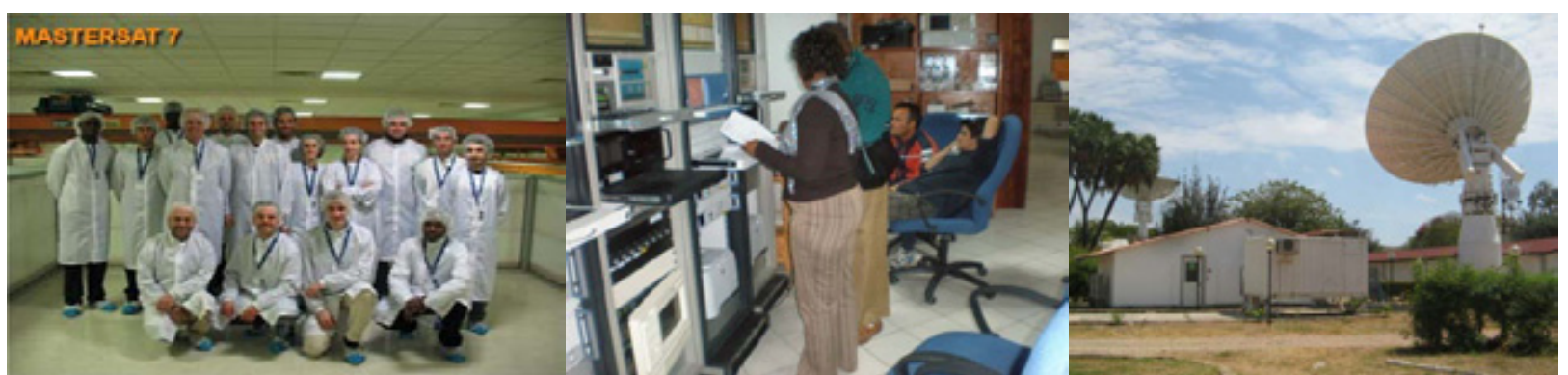

Figure 3: Capacity and infrastructure: The left panel shows a group photograph with three Kenyan students in a satellite Assembly Integration and Test facility while undertaking a Master degree in Italy. The middle panel shows Kenyan technicians working in the Broglio Space Centre (BSC), Malindi. The right panel shows a $12 \mathrm{~m} \mathrm{S-band} \mathrm{tracking} \mathrm{antenna} \mathrm{at} \mathrm{the} \mathrm{BSC} \mathrm{ground} \mathrm{station} \mathrm{in} \mathrm{Kenya.}$ 
the Survey of Kenya will establish the International GNSS Station (IGS Station).

The University of Nairobi is set to put up an observatory for astronomy studies, Jomo Kenyatta University of Agriculture and Technology will soon start a degree course in space sciences and engineering, while Moi University is to be supported in enhancing the Aerospace Engineering and Space Systems course already in existence. Kenya will also continue actively participating in the African Resource Management Satellite Constellation initiative and the Square Kilometre Array radio telescope project with other member countries [5].

Internship programmes are available at the Broglio Space Centre (BSC), for the advancement of students' training. There are also collaborative research projects with the University of Rome La Sapienza (Italy) which would lead to development of Ph.D theses in space science and technology. Training programmes are on course for students and scientists to study in Italy through a bilateral agreement between Kenya and Italy.

\section{Ongoing and Concluded Research}

The satellite data acquisition facility at the BSC has provided data used to conduct various research activities [6]. The following are some of the activities which have been concluded or are in progress at the centre in collaboration with local and international research institutions:

- Profiling of the atmosphere and ozone sounding.

- Aerosol particle pollution in weather and climate change detection and monitoring.

- Land surface temperature, vegetation index and desertification monitoring in the Northern frontier regions of Kenya.

- Ocean surface temperature, chlorophyll and sediment monitoring off the shores of the Kenyan coast and Lake Victoria.

- The detection and monitoring of forest fires in the Horn of Africa region.

Profiling of the atmosphere and Ozone sounding in collaboration with Pennsylvania State University (4 years) and the University of Rome carried out from the Broglio Space Centre with participation of Kenyan researchers. The sounding utilizes the Vaisala radiosondes flown on helium filled balloons to an altitude of about $40 \mathrm{~km}$ as shown in Figure 4. The instrument extracts atmospheric parameters and ozone profiles. Figure 5 shows a graph of tabulated results analyzing the tropopause boundary located at the Kenyan coast.

Aerosol particle pollution research in weather and climate change detection and monitoring has also been carried out in collaboration with NASA. A Sun photometer installed at the centre continuously monitors the aerosol concentrations around the facility and its environs. Figure 6 compares the water vapour profile from the sun photometer against that from the radiosonde.

A research study was carried out by a Kenyan doctorate student on land surface temperature, vegetation index and desertification monitoring in the Northern frontier regions of Kenya as illustrated in Figure 7. This project was carried out in collaboration with the University of Rome "La Sapienza" and coordinated by the San Marco
Project Research Centre. The data used in this study was derived from the NOAA satellites' Advanced Very High Resolution Radiometer (AVHRR) sensor. This data is routinely acquired and is available at the centre.

A research study was also carried out by visiting Kenyan students on ocean surface temperature, chlorophyll and sediment monitoring off the shores of the Kenyan coast and Lake Victoria in collaboration with KEMFRI and BSC. TERRA and AQUA satellites data is available at the centre and the appropriate software for data analysis is also available for this kind of research. Figure 8 shows the effect of the 2004 Tsunami on the abundance of chlorophyll-a off the Somali coast and the Gulf of Aden. Figure 9 illustrates chlorophyll-a and sedimentation levels in the Indian Ocean and Lake Victoria during the period of study.

The detection and monitoring of forest fires in collaboration with the Italian Space Agency is currently on going. This is the most recent research activity taking place at the BSC. A C-band antenna was installed at the centre to acquire Meteosat Second Generation (MSG) data which is used by the system for hotspot detection. Figure 10 shows a web interface used to locate hotspots as detected by the system.

There are other related projects undertaken at the Regional

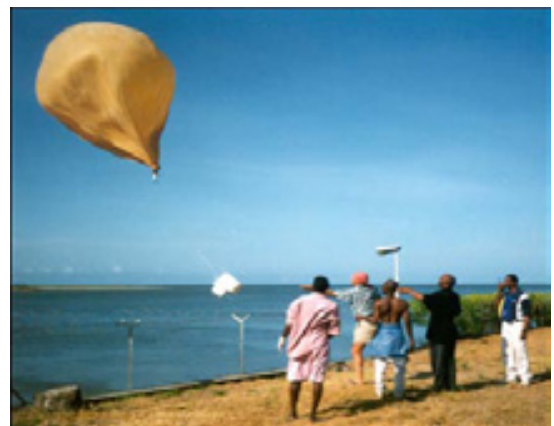

Figure 4: Profiling of the atmosphere at the land-ocean boundary in Malindi Kenya.



Figure 5: Tropopause boundary at the Kenyan Coast indicating height against the day of the year.



Figure 6: Water vapour profiling. 

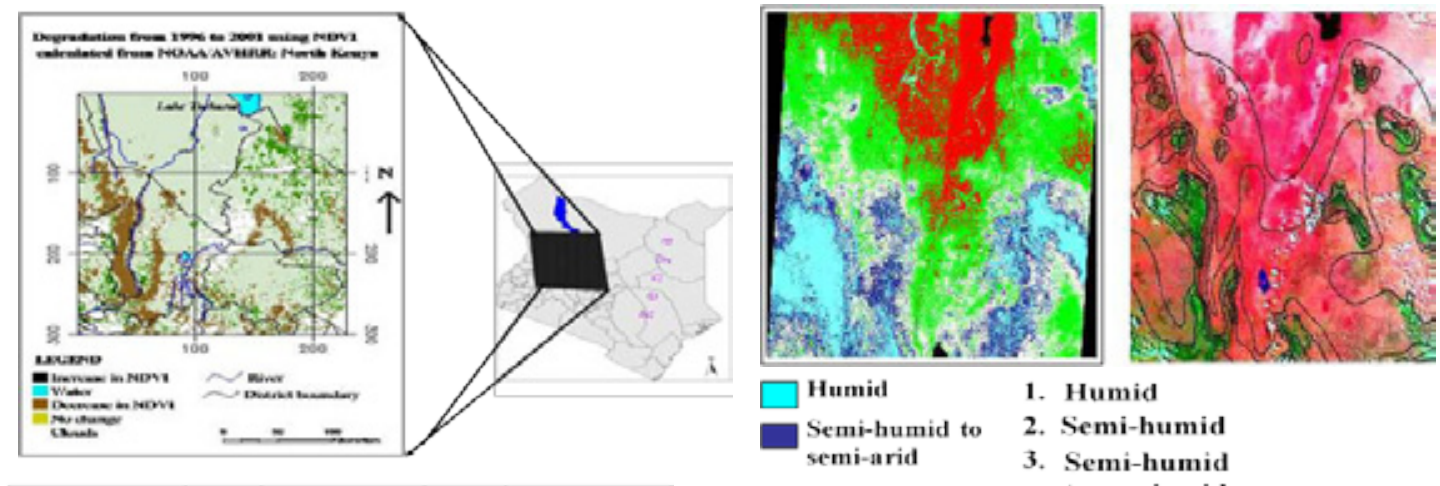

\begin{tabular}{|c|c|c|c|c|}
\hline IMAGE & Series & Dry staton & Serics & Wet sexson \\
\hline NOWNAVHRR & II & February-1959 & 11 & May-1959 \\
\hline NOW/AVHRR & 14 & February-1991 & is & May-1991 \\
\hline NOA & 14 & February-1996 & 14 & Juty -1996 \\
\hline NOWNAVHRR & 14 & February-2001 & 16 & April-2001 \\
\hline I anduat & TM & January-1986 & TM & July -1986 \\
\hline Landsat & $T M$ & Februan-1995 & & \\
\hline Landsat & ETM & Februsn-2001 & ETM & May-2001 \\
\hline
\end{tabular}

$\square$ Semi-Arid

3. Semi-humid

Arid

4. Semi-arid

Very Arid

5. Arid

6. Very Arid

Figure 7: Desertification monitoring in Northern Kenya

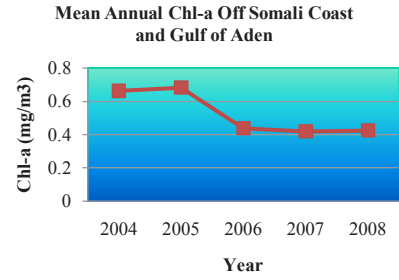

Figure 8: Chlorophyll-a levels off the Somali coast and Gulf of Aden after the December 2004 Tsunami.

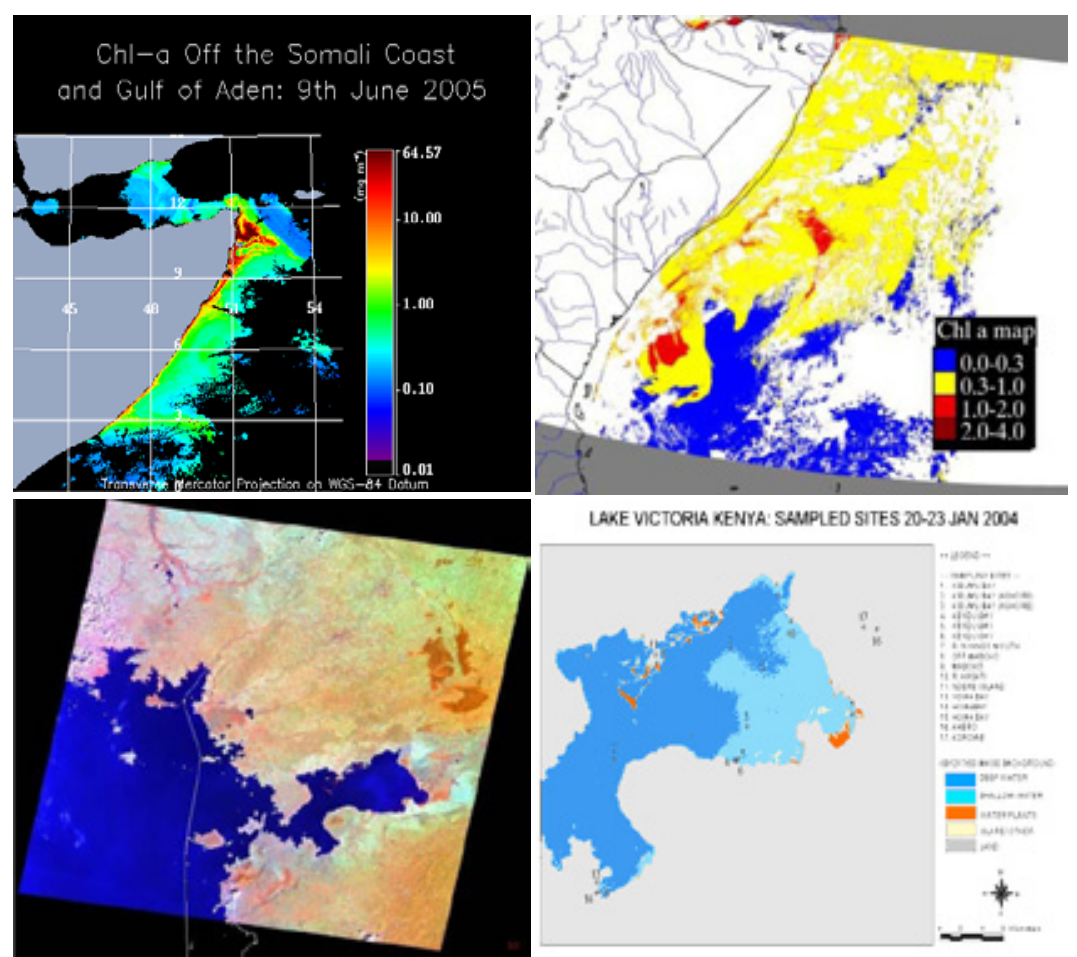

Figure 9: Chlorophyll-a and sedimentation levels in the Indian Ocean and Lake Victoria. 
Centre for Mapping of Resources for Development (RCMRD), and studies carried out at the Kenya Meteorological Department (KMD) and IGAD Climate Prediction and Applications Centre (ICPAC) for the Horn of Africa region, based in Nairobi. The output of these projects go a long way to advise member states on sound resource management, climate prediction and disaster mitigation measures, and capacity development. These demonstrate what space science and technology can offer to the society.

Other collaborative programmes exist with NASA, the Italian Space Agency and other international institutions (Figure 11).

\section{Short and Long Term Perspectives}

The Tracking, Telemetry and Command Station at Broglio Malindi Space Centre under the San Marco Project has been in operation since 1964 and is currently owned and managed by the Italian Space Agency (ASI). This centre is part of ASI/ESA ground stations network whose operations originally included launch activities and support of satellites until 1988. Presently the centre is devoted to satellite tracking and data acquisition. This facility continues to offer invaluable experience to Kenyans [6].

The functions of the Kenya Space Agency would be decentralized so that each region acts as a centre of excellence in space science



Figure 10: Detection and monitoring of forest fires.



Figure 10: Detection and monitoring of forest fires and technology. Nominated locations for the various departments are: Isiolo/Nakuru for Earth Observation/Ground Station, Kisumu for Communications \& Navigation, Eldoret/Machakos for Space Exploration and Publications \& Outreach, Coast region for launch activities, and Nairobi for Mission/Payload design, Research \& Development and also act as the Mission Operations and Control Centre and Headquarters. There are already existing institutions to act as local depositories since they are well established and utilize a lot of satellite data [7].

The country needs to be self sufficient in satellite data acquisition for territorial surveillance, mapping of land and coastal resources including the Kenya extended economic zone, environmental assessment (atmosphere and land), and collaboration with the other East African countries.

Cooperation in rocket launches is necessary since Kenya is located at an appropriate site ideal for equatorial based launches. There is also urgent need to establish an autonomous Earth Ground station for tracking, telemetry and command. Isolio or Nakuru are strategic locations for this establishment.

\section{Challenges}

Realization of the space policy however, may be hampered by political, bureaucratic and financial considerations. Discussions are ongoing to address the appropriate government agency to coordinate space activities and essentially host the Kenya Space Agency. There is still need to enhance capacity building programmes, and provide resources to meet the high cost of accessing space technology. So far, there is no indigenous infrastructure and satellites for national use, and there is limited legislation necessary to support space activities.

\section{Conclusions}

Kenya has achieved a lot over the years since the launch of the first satellite not only in Kenya but in Africa in 1964. Kenya, in the context of the East African Community states, is going to be a regional focal point for space science and technology activities. The strategy is to overcome some of the challenges in the next five years.

\section{References}

1. www.vision2030.go.ke

2. www.nepad.org.

3. www.ict.go.ke.

4. Report on the Establishment and Structure of the National Space Secretariat (2011) Taskforce on Operationalization of the National Space Secretariat.

5. Algiers, Algeria $7^{\text {th }}$ December 2009. Memorandum of Understanding on the African Resources Management Satellite Constellation (ARMC), Third African Leadership Conference on Space Science and Technology for Sustainable Development.

6. Laneve G, Santilli G, Cadau E, Fusilli L, Argento G, et al. (2010) Short description of the Remote Sensing activities at the BSC - Malindi for Master in Satellites and Orbital Platforms. Centro di Ricerca Progetto San Marco (CRPSM) University of Rome 'La Sapienza' Università di Roma.

7. Kenya National Space Strategy (2012) National Council for Science and Technology.

\section{Author Affiliations}

Top

${ }^{1}$ Italian Space Agency (Broglio Space Centre - Malindi), Nairobi, Kenya ${ }^{2}$ Ministry of State for Defence, Nairobi, Kenya

${ }^{3}$ National Council for Science and Technology, Nairobi, Kenya 